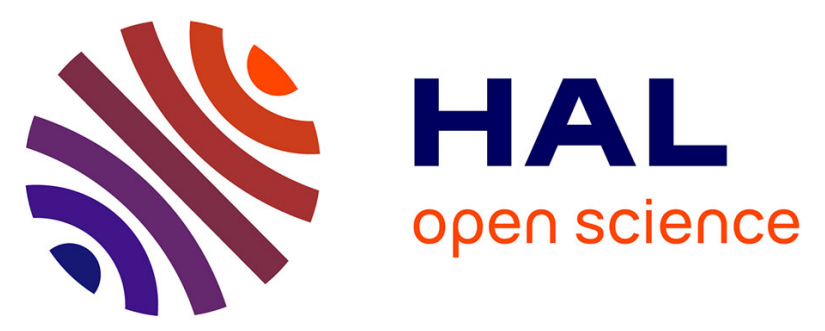

\title{
Interactions of the Rad51 inhibitor DIDS with human and bovine serum albumins: Optical spectroscopy and isothermal calorimetry approaches
}

Denis Velic, Cathy Charlier, Milena Popova, Titouan Jaunet-Lahary, Zakaria Bouchouireb, Sebastien Henry, Pierre Weigel, Jean-Yves Masson, Adele D. Laurent, Igor Nabiev, et al.

\section{To cite this version:}

Denis Velic, Cathy Charlier, Milena Popova, Titouan Jaunet-Lahary, Zakaria Bouchouireb, et al.. Interactions of the Rad51 inhibitor DIDS with human and bovine serum albumins: Optical spectroscopy and isothermal calorimetry approaches. Biochimie, 2019, 167, pp.187-197. 10.1016/j.biochi.2019.09.016 . hal-02359114

\author{
HAL Id: hal-02359114 \\ https://hal.science/hal-02359114
}

Submitted on 17 Nov 2020

HAL is a multi-disciplinary open access archive for the deposit and dissemination of scientific research documents, whether they are published or not. The documents may come from teaching and research institutions in France or abroad, or from public or private research centers.
L'archive ouverte pluridisciplinaire HAL, est destinée au dépôt et à la diffusion de documents scientifiques de niveau recherche, publiés ou non, émanant des établissements d'enseignement et de recherche français ou étrangers, des laboratoires publics ou privés. 
Interactions of the Rad51 Inhibitor DIDS with Human and Bovine Serum Albumins: Optical Spectroscopy and IsoThermal Calorimetry Approaches

Denis Velic ${ }^{1,2+}$, Cathy Charlier $^{1+}$, Milena Popova ${ }^{1}$, Titouan Jaunet-Lahary ${ }^{3}$, Zakaria Bouchouireb $^{3}$, Sébastien Henry ${ }^{1}$, Pierre Weigel ${ }^{1}$, Jean-Yves Masson ${ }^{2}$, Adele Laurent ${ }^{3}$, Igor Nabiev $^{4-6}$, Fabrice Fleury ${ }^{1, *}$

${ }^{1}$ Group of Mechanism and Regulation of DNA Repair and IMPACT platform, UFIP UMR CNRS 6286 / University of Nantes, 44322 Nantes, France

${ }^{2}$ Centre de Recherche en Cancérologie de l'Université Laval, Laboratoire de Stabilité du Génome, 9, rue McMahon, G1R 3S3, Québec, Canada

${ }^{3}$ Laboratoire CEISAM - UMR CNR 6230, Université de Nantes, 2 Rue de la Houssinière, BP 92208, 44322 Nantes Cedex 3, France

${ }^{4}$ Laboratoire de Recherche en Nanosciences EA4682-LRB, Université de Reims ChampagneArdenne, 51100 Reims.

${ }^{5}$ National Research Nuclear University MEPhI (Moscow Engineering Physics Institute), 31 Kashirskoe shosse, 115522 Moscow, Russian Federation.

${ }^{6}$ Department of Clinical Immunology and Allergology, Sechenov First Moscow State Medical University, 119992 Moscow, Russian Federation

* Corresponding author E-mail: fleury-f@univ-nantes.fr 


\begin{abstract}
Rad51 is a key protein in DNA repair by homologous recombination and an important target for development of drugs in cancer therapy. 4'-diisothiocyanostilbene-2,2'-disulfonic acid (DIDS) has been used in clinic during the past 30 years as an inhibitor of anion transporters and channels. DIDS has been demonstrated to affect Rad51-mediated homologous pairing and strand exchange, key processes in homologous recombination. Consequently, DIDS has been considered as a potential revertant of radio- and chemo-resistance of cancer cells, the major causes of therapy failure.

Here, we have investigated the behavior of DIDS towards serum albumins. The effects of environmental factors, primarily, solvent polarity, on DIDS stability were evaluated, and the mechanisms of interaction of DIDS with human or bovine serum albumin were analyzed using isothermal calorimetry, circular dichroism and fluorescence spectroscopies. DIDS interaction with both serum albumins have been demonstrated, and the interaction characteristics have been determined. By comparing these characteristics for several DIDS derivatives, we have identified the DIDS moiety essential for the interaction. Furthermore, site competition data indicate that human albumin has two DIDS-binding sites: a high-affinity site in the IIIA subdomain and a low-affinity one in the IB subdomain. Molecular docking has revealed the key molecular moieties of DIDS responsible for its interactions in each site and shown that the IB site can bind two ligands. These findings show that binding of DIDS to serum albumin may change the balance between the free and bound DIDS forms, thereby affecting its bioavailability and efficacy against Rad51.
\end{abstract}

\title{
Keywords
}

Stilbene inhibitors; blood albumin; DNA repair; protein-ligand interaction.

\section{Highlights (3-5 points)}

- Identification of the chemical moieties of DIDS involved in the interaction with albumins

- DIDS binding site is located in subdomains IB and IIIA of albumins

- DIDS binding to albumins could affect its interaction with Rad51 target 


\begin{abstract}
Abbreviations
DIDS, 4'-diisothiocyanostilbene-2,2'-disulfonic acid; DAZDS, 4'-diazidostilbene-2,2'disulfonic acid; DADS, 4'-diaminostilbene-2,2'-disulfonic acid, ANS, 8-anilino-1naphthalenesulfonic acid; DMSO, Dimethyl sulfoxide; PBS, phosphate buffer saline; HSA, human serum albumin; BSA, bovine serum albumin; ITC, isothermal calorimetry; CD, circular dichroism; War, warfarin; Ibu, ibuprofen; BR, bilirubin; BV, biliverdin.
\end{abstract}




\section{Introduction}

Since the early 1970s 4,4'-diisothiocyanatostilbene-2,2'-disulfonic acid, known as DIDS (Figure 1), has been used as a one of the few efficient chloride channel blockers [1]. Although DIDS may not be used as a drug for treatments of bone and kidney diseases provoked by mutations of these channels, a study has shown that DIDS also acts as an inhibitor of Rad51mediated processes [2]. Rad51 is an eukaryotic protein with a key role in the homologous recombination repair pathway, which is an accurate pathway for DNA double-strand break repair. Rad51 binds to the single-stranded tails of the break and forms a helical nucleofilament which allows homologous pairing and strand exchange with a homologous sequence in order to carry out DNA repair [3]. Overexpression of Rad51 is frequently found in tumor cells, which suggests that this protein promotes tumorigenesis and cell resistance to treatment. In the past decade, a large number of publications have proposed this protein as a new therapeutic target [4-8]. Several studies were focused on inhibiting different steps of Rad51mediated homologous recombination by small molecules [2, 9-11]. Recently a phase 1/2 clinical trial has been proposed in the last AACR meeting using a Rad51 inhibitor associated with PARP inhibitor [12].

Prior to in vivo assays or therapeutic use, it would be interesting to assess the behavior of DIDS in the presence of the most abundant protein in blood plasma, human serum albumin (HSA). Indeed, it has been shown that the distribution, the available concentration and the metabolism of numerous drugs can be significantly altered by their binding to HSA [13].

HSA shares about 80 percent of sequence similarity with bovine serum albumin (BSA). Both proteins have three domains (I, II and III), each composed of two subdomains, A and B [13]. HSA has at least three main binding pockets located in subdomains IB, IIA, and IIIA. Most compounds bind to a single site, however, some have two or more binding sites. Carter et al [14] have estimated that $39 \%, 19 \%$, and $27 \%$ of the compounds are found at three major sites IB, IIA, and IIIA, respectively. However, the contribution of each site to ligand transport is not clearly established.

The distribution, available concentration, and elimination rate of many drugs can be significantly altered by their binding to HSA [13]. Using different biophysical techniques, including circular dichroism (CD), fluorimetry, UV-vis spectrophotometry, and isothermal titration calorimetry (ITC), we have obtained evidence for the interaction between DIDS and human and bovine albumins. We have also identified and characterized the binding sites for DIDS on these proteins. Our data suggests that DIDS may bind efficiently to serum albumin proteins. This interaction may change the balance between the free and bound DIDS forms, thus affecting its bioavailability and inhibitor efficiency against the Rad51 protein. 


\section{Materials and Methods}

\subsection{Chemicals and proteins}

DIDS, its derivatives, and human and bovine serum albumins were purchased from SigmaAldrich Chemical Co. Both proteins (>99\% purity) are essentially fatty-acid- and globulinfree. Stock solutions of DIDS and its analogs were prepared in water at a concentration of 10 $\mathrm{mM}$ and then diluted in PBS.

\subsection{UV-Vis. absorption spectroscopy}

UV-vis spectra (from 300 to $450 \mathrm{~nm}$ ) were recorded with a Jasco V-530 UV-visible scanning spectrophotometer equipped with a Peltier temperature controller. The measurements were performed using quartz cells with a path length of $1 \mathrm{~cm}$. The experimental conditions are described in the figure legends.

\subsection{Fluorescence spectroscopy}

A Jasco spectrofluorometer, model FP-6500, was used for fluorescence measurements. The slit widths used for excitation $(350 \mathrm{~nm})$ and emission $(380-600 \mathrm{~nm})$ were 1 and $3 \mathrm{~nm}$, respectively. The measurements were made using a $1 \mathrm{~cm} \times 0.2 \mathrm{~cm}$ quartz cell at $25^{\circ} \mathrm{C}$. Fluorescence emission intensity data were collected directly on a computer connected to the spectrofluorometer and were analyzed using the Jasco Spectra Manager software. A 10- $\mu \mathrm{M}$ DIDS solution was titrated successively by HSA and BSA solutions.

ANS was used to probe the hydrophobic surfaces of HSA and BSA. The fluorescence emission was measured from 400 to $600 \mathrm{~nm}$ for $\lambda_{\mathrm{ex}}=370 \mathrm{~nm}$. The data were corrected for the effect of solvent on the intrinsic ANS fluorescence by subtracting the ANS fluorescence spectra in the absence of protein for each DIDS concentration.

\subsection{Isothermal titration calorimetry}

Automated titrations of BSA and HSA with different ligands were conducted by means of isothermal titration calorimetry (iTC) using an Auto-iTC 200 microcalorimeter (MicroCal, Northampton, MA, USA). The experiments were carried out at $22^{\circ} \mathrm{C}$ in PBS. The reference cell was filled with deionized water, and the BSA or HSA protein solution $(70 \mu \mathrm{M})$ was 
loaded into the sample cell. The syringe was filled with a solution of DIDS and its derivatives ( $2 \mathrm{mM}$ ). Titrations were performed with 20 successive injections of $2 \mu \mathrm{L}$ of the ligand in the sample cell. A 150-s time interval between the injections was used in order to ensure complete thermal equilibration after each injection. The same titration was used for site competition experiments, but HSA was preincubated with one of the three competitor ligands (warfarin, ibuprofen, or bilirubin) at concentrations of 50 or $500 \mu \mathrm{M}$. The titration experiments were made at least in triplicate.

Control experiments were performed by injection of the buffer into the protein solution under identical conditions and yielded insignificant heats of dilution.

Data analysis was carried out using the Microcal Origin 7.0 software; the data were fitted with the one- or two- set of site model. Experimental data yielded the association constant (Ka), stoechiometry $(\mathrm{n})$, and molar enthalpy binding $(\Delta \mathrm{H})$ values. The reaction entropy was calculated using the equations $\Delta \mathrm{G}=\Delta \mathrm{H}-\mathrm{T} \Delta \mathrm{S}=-\mathrm{RT} \ln \mathrm{K}_{\mathrm{a}}$, where $\mathrm{T}$ is the absolute temperature and $\mathrm{R}=1.9872 \mathrm{cal} \mathrm{mol}^{-1} \mathrm{~K}^{-1}$.

\subsection{Circular dichroism measurements}

The circular dichroism (CD) spectra of small molecules were measured using a J-810 spectropolarimeter (Jasco, Japan) and a mini-quartz cell with a path length of $1 \mathrm{~cm}$. The spectra were recorded in the range from 385 to $525 \mathrm{~nm}$ and averaged over three scans to increase the signal-to-noise ratio [15] (response time, $0.125 \mathrm{~s}$; resolution, $0.1 \mathrm{~nm}$ ). The final concentrations of DIDS and HSA were 0-300 $\mu \mathrm{M}$ and $70 \mu \mathrm{M}$, respectively, in phosphate buffer saline (PBS), pH 7.4. Warfarin, ibuprofen, bilirubin, and biliverdin were used as competitor ligands at concentrations of $50 \mu \mathrm{M}$.

\subsection{Molecular modeling study}

The standard docking protocol was employed to dock DIDS into different binding pockets of HSA. Since no crystallographic data exist for DIDS embedded into HSA, three potential binding sites (IB, IIA, and IIIA) were considered, as in the experiments. Starting from the following crystallized structure of BR, War, or Ibu ligand embedded into HSA (e.g., 2VUE, 2BXD and 2BXG pdb code). For the ligand, a set of initial ligand conformations were produced using the Confgen module [16] of the Schrödinger suite 2015-1 [15]. The Glide Glide v6.6 module [17] was then employed to dock each conformation into each binding site. The multistep Schrödinger's Protein Preparation Wizard was employed to prepare the HSA 
protein. 578 residues (residues 5-582) were considered, and the terminal $\mathrm{N}$ (C) was replaced with the $\mathrm{NH}_{3}{ }^{+}\left(\mathrm{COO}^{-}\right)$chemical function. PROPKA 3.0 was used to set up all protonation states. A pH of 7.4 was used to ensure correspondence with biological conditions, the lysine and arginine (aspartate and glutamate) residues were (de)protonated, except for Lys199, which was deprotonated, and Glu244 and His9, which were protonated, as described in the literature [18-20]. For the docking, a grid generation was used to prepare structural inputs and to define all binding sites. The protein residues inside the $10(30) \AA^{3}$ box, centered in the ligand, were included to define the inner (outer) box. The extra-precision (XP) [21] mode of the docking algorithm was employed to dock DIDS. All docking simulations were conducted with a maximum of 10000 poses per ligand, whose 1000 best poses were chosen for energy minimization. All other parameters were maintained at their default settings, except of an aromatic hydrogens which were considered as the donors. The OPLS-AA force field was used to estimate the ligand-HSA minimization energies [22]. For each binding site, clustering steps have been performed using the linkage average algorithm to facilitate the pose selection.

\section{Results and Discussion}

3.1 Effect of solvent polarity on the physico-chemical proprieties of DIDS.

The physico-chemical characteristics of DIDS were investigated by UV-vis spectrophotometry and fluorescence spectroscopy. The DIDS absorption spectra in different solvents were recorded. Figure 2A shows that the position and shape of the DIDS absorption maximum strongly depend on the solvent polarity. Indeed, the absorption maximum position shifts from $350 \mathrm{~nm}$ in water to $372 \mathrm{~nm}$ in DMSO, which corresponds to a bathochromic shift with a decrease in solvent polarity.

We have further measured the fluorescence emission spectra of DIDS as a function of the ethanol content in the aqueous buffer. The data showed that, although the positions of the maxima of the fluorescence emission spectra of DIDS were only slightly shifted, the fluorescence emission intensity of DIDS in an aqueous buffer was twofold higher than that in ethanol. Therefore, changes of the solvent polarity strongly modify the spectral characteristics of DIDS. These results confirm our recent theoretical and experimental data on the structural and optical properties of DIDS [23].

3.2Evidence of the interaction of DIDS with human and bovine serum albumins.

Figure 3 shows the results of titration of DIDS by BSA and HSA in a buffer solution using the UV-vis and fluorescence spectroscopic approaches. An increase in the concentration of BSA 
or HSA caused considerable changes in the spectra of DIDS. Upon addition of albumins, we observed a decrease in UV-vis DIDS absorbance. These spectral modifications appear to have been similar for BSA and HSA (Figures 3A and 3B). Thus, our study is the first to show that DIDS interacts with both proteins, HSA and BSA.

The interaction between DIDS and HSA or BSA was further confirmed using the fluorescence approach. We performed titration analysis as described above. The results clearly show a diminution of the DIDS signal with an increase in protein concentration. Figure 3 shows that the fluorescence emission intensity of DIDS decreased by a factor of 2-3 in the presence of 4.5 $\mu \mathrm{M}$ of HSA and BSA. The protein mediated-diminutions of fluorescence intensity of DIDS spectra were similar to those observed upon a decrease in the polarity of the DIDS solvent (Figure 2B) suggesting that the residues in the vicinity of bound DIDS are likely in buried hydrophobic/apolar site.

In order to analyze the environment of protein-bound DIDS, we used 8-anilino-1naphthalenesulfonic acid (ANS), a fluorescent compound known as a probe for hydrophobic binding sites of proteins [24-26]. Free ANS fluoresces weakly in an aqueous solution, and its fluorescence at about $470 \mathrm{~nm}$ strongly increases when it binds to buried hydrophobic sites [27]. The fluorescence of ANS in the presence of HSA and BSA provides information on all the hydrophobic binding sites of these proteins. As shown in Figure 4, ANS fluorescence strongly increases in the presence of HSA or BSA. When DIDS was added to the albumin/ANS complex, ANS fluorescence emission decreased with increasing DIDS concentration from 0 to $20 \mu \mathrm{M}$.

This finding provides clear evidence that DIDS replaces ANS from its albumin-binding site(s), suggesting that DIDS and ANS bind to the same site or in vicinity binding site. The data also indicate that the DIDS-binding site has a hydrophobic environment for both HSA and BSA proteins. It is noteworthy that ANS and DIDS have two negatively charged sulfonate groups that may strongly bind to positively charged residues within the albumin binding sites [26].

\subsection{Identification of structural determinants of DIDS involved in the interaction}

ITC titration allows the measurement of heat exchange induced by the interaction between a protein and a ligand. In our case, we performed titrations of HSA and BSA with DIDS and its derivatives.

First, the ITC titrations of HSA and BSA with DIDS (Figures 5A, 5B) have shown considerable heat exchange, confirming the interaction between DIDS and both serum 
albumins. Initially positive, the enthalpy becomes negative when the ligand-to-protein molar ratio rises above two unity. This result indicates that the association reaction is endothermic at two molar ratio below unity and becomes exothermic above this value. This enthalpy variation demonstrates that there are at least two types of binding sites for DIDS in both proteins. As described in "Materials and Methods", we fitted all data points and calculated several binding parameters, including the stoichiometric number $\mathrm{N}$ and binding constant $\mathrm{Ka}$ (Table 1). We found that, for both HSA and BSA proteins, there are high-affinity and lowaffinity DIDS-binding sites. The Ka values of DIDS for the high-affinity sites were $3.37 \times 10^{6}$ $\mathrm{M}^{-1}$ and $2.08 \times 10^{6} \mathrm{M}^{-1}$ for HSA and BSA, respectively, whereas for the low-affinity sites, the Ka were 100-fold lower. Regarding the stoichiometry of interaction, it seems that only one DIDS ligand binds to the high-affinity site, while two or three ligands interact with the lowaffinity binding site of either HSA or BSA. Hence, DIDS behaves similarly with regard to HSA and BSA, which suggests that the binding sites of both proteins are identical or similar. The same analysis is performed with DIDS analog, DAZDS, and the binding parameters are presented in the table 2 . It note that the affinity constant Ka of DAZDS for HSA $\left(4.1210^{5} \mathrm{M}^{-}\right.$ ${ }^{1}$ ) or BSA (9.12 $\left.10^{5} \mathrm{M}^{-1}\right)$ were 10-fold lower than Ka of DIDS demonstrating a weak affinity of both proteins for DAZDS. Like the high affinity interaction site for DIDS, the stoichiometric number $\mathrm{N}$ was one, suggesting one bound DAZDS ligand in this site for both HSA and BSA proteins (Table 2).However ITC titration does not allow the characterization of a second interaction site (Not Determined in the Table 2) for DAZDS, likely because of the very low affinity. This affinity difference between DIDS and DAZDS provides evidence that the substituted chemical groups are involved in the HSA and BSA interaction.

Second, in order to identify the chemical groups of DIDS involved in these protein-ligand interactions, we used two other DIDS analogs where the isothiocyanate group was replaced by an azido (DAZDS) or an amino (DADS) group (Figure 1).

The same experiments have been performed with the DIDS derivatives. ITC titration with DAZDS results in a response similar to that observed with DIDS: the association reaction is first endothermic and then exothermic, when the ligand-to-protein molar ratio rises above unity (Figures 5C, 5D). However, the association enthalpy is slightly smaller in the case of DIDS. As with DIDS, the ligand behavior was found to be the same for DAZDS interactions with HSA and BSA.

The titrations with the DADS ligand are very interesting, since there is almost no ITC signal. This shows that DADS does not interact with HSA or BSA, which is likely to result from the presence of an amino group. Thus, the position of this chemical group of stilbene is important for the interaction. 


\subsection{Localization of DIDS-binding sites in HSA}

HSA has three main binding sites, 1, 2, and 3, located in subdomains IIA, IIIA, and IB, respectively [18]. X-ray crystallography has shown that a large number of ligands are specific for each binding site. For example, warfarin (War), ibuprofen (Ibu), and bilirubin (BR) have been reported to bind to subdomains IIA, IIIA, and IB, respectively [28, 29]. In order to identify the binding sites for DIDS, we probed the ability of DIDS to displace these albuminbinding drugs from their respective binding sites. Therefore, we preincubated HSA with the above-mentioned competitor ligands before carrying out ITC and CD titrations with DIDS.

Figure 6 shows the ITC titrations with DIDS of HSA alone and HSA complexed with War, Ibu, or BR. Preincubation with Ibu induced a slight signal variation in comparison with HSA alone at HSA-to-Ibu ratios of 2:1 and 1:5, whereas no variation was observed in the case of HSA complexed with War at the same ratios (Figure 6A). This result provides evidence that the War-binding site is not involved in the interaction of DIDS with HSA. The most significant variations in the obtained profiles were observed when HSA was preincubated with BR and especially when the BR concentration was five times higher than the HSA one (Figure 6C).

We hypothesized that the primary binding site for DIDS is located in subdomain IIIA (Ibu site). The secondary binding site could involve subdomain IB (BR site), while site IIA is certainly not involved in the interaction.

To test this hypothesis, we preincubated HSA with bilirubin and titrated the resultant HSA/BR complex with DIDS in CD experiments. In the presence of HSA, BR displays a high induced circular dichroism (ICD) signal caused by its binding to HSA. This optical property is described in detail in many publications and is often used to prove the involvement of subdomain IB in protein-ligand interactions [30-32].

As shown in Figure 7, the CD signal of BR alone was almost zero at $50 \mu \mathrm{M}$. The addition of HSA induces the ICD signal of BR in the form of a positive band at $475 \mathrm{~nm}$ and a negative band at $420 \mathrm{~nm}$. The titration of the HSA/BR complex by DIDS leads to a decrease in the intensity of the ICD signal, confirming that DIDS and BR compete for binding to the same site. The same experiment was performed with DAZDS, which resulted in a similar competition with BR, whereas the titration with DADS had a clearly less pronounced effect.

The interpretation of these competition assays is complicated by the presence of more than one binding site for the displaced molecule. This is the case for BR. HSA has one highaffinity $\left(\mathrm{Ka}=10^{8} \mathrm{M}^{-1}\right)[33,34]$ and one or two low-affinity binding sites for bilirubin [31, 35]. The IIIA site has been suggested to be of low affinity [31]. A number of studies have been 
conducted in order to determine the location of the primary binding site; however, the results are contradictory. Some authors have presented evidence that BR can bind to the IIA site with a high affinity $[31,36,37]$. However, many studies have shown the IB site to be the primary binding site $[35,38]$. We have probed the ability of War to displace pre-bound BR from the HSA molecule in order to determine whether the two molecules bind to the same site. War reduced the $\mathrm{BR}$ CD signal by $50 \%$ at much higher concentrations than DIDS. This demonstrates that the IIA site is not the primary binding site for BR. Thus, our results suggest that DIDS binds with a high affinity to the IB site.

To confirm this result and to eliminate any doubt related to the presence of secondary binding sites for bilirubin on HSA, we conducted the same CD experiments using biliverdin. Biliverdin is known to bind to only one site on HSA, IB [38]. As shown in Figure 8, DIDS and DAZDS displaced BV from its binding site, whereas DADS had no effect. This confirms that DIDS and DAZDS bind primarily to the IB site.

As in the experiments, the IB and IIIA sites are the most favorable pockets to bind the ligand using the docking procedure. The IIIA binding site is known to be a hydrophobic pocket mainly consisting of apolar residues (Leu, Ala, Gly, and Ile). The entrance of the binding site is, however, characterized by polar and charged amino acids, including Asn391, Arg410, Lys414, and Ser489. The IIIA site is known to efficiently bind non-steroidal aromatic carboxylate (e.g., Ibu). DIDS, containing two sulfonate groups, is undoubtedly a candidate ligand for this binding site [39, 40]. The obtained best pose revealed that four specific interactions are established with the ligand's sulfonate groups. Two hydrogen bonds (hereinafter, H-bonds) are formed with Asn391 and Tyr411, and a salt bridge is formed between Arg410 and one of the sulfonate groups. Arg410 is also involved into a $\pi$-cation interaction with one of the aromatic cycles of DIDS (Figure 9, right). The IB binding site is known to be hydrophobic, quite large, and flexible: it binds, e.g., heme, bilirubin, and biliverdin [29]. First, the best pose for a single DIDS was determined; it exhibited numerous strong interaction between the ligand and its neighbors: specific H-bonds with His146 and Arg117 and a salt bridge between Lys190 and one of the sulfonate group. Since the binding pocket was large, it was shown that a second DIDS can easily be bound within the 1B site, as the experimental data suggested. The second DIDS is stabilized by strong salt bridges with Lys137 and forms H-bonds with Thr133, Asn120, and Phe134 (see Figure S2). Note that docking was also performed within the IIA site, but only a limited number of poses of DIDS were located within the hydrophobic pocket, while the majority of them were outside the pocket, which may be explained by the small size of the IIA pocket. 


\section{Conclusion}

In this study, we demonstrated that the primary, high-affinity binding site of DIDS in HSA is located in subdomain IIIA, while the secondary, low-affinity binding site could be located in subdomain IB.

In the past decade, resurgence of interest has occurred in the development of inhibitors targeting DNA repair pathways [41]. Since 2009, when DIDS was discovered as a potential Rad51 inhibitor, at least seven other small molecules have been described as inhibitors of this human recombinase. These molecules, coupled with anti-cancer drugs, could improve chemotherapy by killing more effectively Rad51-mediated resistant cancer cells [42]. Understanding the interaction between Rad51 inhibitors and HSA is a pivotal element for understanding the pharmacokinetics and pharmacodynamics of these inhibitors. Indeed, the interaction with HSA could play the dominant role in the bioavailability of anticancer drugs such as DIDS.

Our data show that the potential interaction with blood proteins should be taken into consideration when developing more effective DIDS derivatives against Rad51. DIDS derivatives not interacting with these circulating proteins while remaining effective against Rad51 may become the serious candidates to sensitize resistant cancers with altered Rad51 activity.

\section{Acknowledgments}

This study was supported by grants from the Ligue Contre le Cancer (Comité 44) and from Program Samuel-De-Champlain grant (n ${ }^{\circ}$ 63/104). SH and DV are supported by a fellowship from the Region Pays de la Loire (CIMATH2). T. J.-L. thanks the Région Pays de la Loire (MES-TransMED) for his PhD grant. A.D.L. and F. F. acknowledge the Région des Pays de la Loire for financial support within the framework of MES-TransMed Pari Scientifique. This research used resources of (1) the GENCI-CINES/IDRIS (Grants c2016085117) and (2) CCIPL (Centre de Calcul Intensif des Pays de Loire). This study was also supported by the Ministry of Education and Science of the Russian Federation, State Contract no. 16.1034.2017/ПЧ (to I.N.). 


\section{References}

[1] Wulff H., New light on the "old" chloride channel blocker DIDS, ACS Chem Biol 3 (2008) 399-401.

[2] Ishida T., Takizawa Y., Kainuma T., Inoue J., Mikawa T., Shibata T., Suzuki H., Tashiro S., Kurumizaka H., DIDS, a chemical compound that inhibits RAD51-mediated homologous pairing and strand exchange, Nucleic Acids Res 37 (2009) 3367-3376.

[3] Nomme J., Renodon-Corniere A., Asanomi Y., Sakaguchi K., Stasiak A.Z., Stasiak A., Norden B., Tran V., Takahashi M., Design of potent inhibitors of human RAD51 recombinase based on BRC motifs of BRCA2 protein: modeling and experimental validation of a chimera peptide, J Med Chem 53 (2010) 5782-5791.

[4] Huang J.W., Wang Y., Dhillon K.K., Calses P., Villegas E., Mitchell P.S., Tewari M., Kemp C.J., Taniguchi T., Systematic screen identifies miRNAs that target RAD51 and RAD51D to enhance chemosensitivity, Mol Cancer Res 11 (2013) 1564-1573.

[5] Nagathihalli N.S., Nagaraju G., RAD51 as a potential biomarker and therapeutic target for pancreatic cancer, Biochim Biophys Acta 1816 (2011) 209-218.

[6] Scott D.E., Coyne A.G., Venkitaraman A., Blundell T.L., Abell C., Hyvonen M., Small-molecule inhibitors that target protein-protein interactions in the RAD51 family of recombinases, ChemMedChem 10 (2015) 296-303.

[7] Velic D., Couturier A.M., Ferreira M.T., Rodrigue A., Poirier G.G., Fleury F., Masson J.Y., DNA Damage Signalling and Repair Inhibitors: The Long-Sought-After Achilles' Heel of Cancer, Biomolecules 5 (2015) 3204-3259.

[8] Martinez S.F., Renodon-Corniere A., Nomme J., Eveillard D., Fleury F., Takahashi M., Weigel P., Targeting human Rad51 by specific DNA aptamers induces inhibition of homologous recombination, Biochimie 92 (2010) 1832-1838.

[9] Budke B., Tueckmantel W., Miles K., Kozikowski A.P., Connell P.P., Optimization of Drug Candidates That Inhibit the D-Loop Activity of RAD51, ChemMedChem 14 (2019) 1031-1040.

[10] Hengel S.R., Spies M.A., Spies M., Small-Molecule Inhibitors Targeting DNA Repair and DNA Repair Deficiency in Research and Cancer Therapy, Cell Chem Biol 24 (2017) 1101-1119.

[11] Lamont K.R., Hasham M.G., Donghia N.M., Branca J., Chavaree M., Chase B., Breggia A., Hedlund J., Emery I., Cavallo F., Jasin M., Ruter J., Mills K.D., Attenuating homologous recombination stimulates an AID-induced antileukemic effect, J Exp Med 210 (2013) 1021-1033.

[12] Maclay T., Day M., Mills K.D., CYT01B, a novel RAD51 inhibitor, acts synergistically with PARP inhibitors, AACR Annual Meeting 2019, Atlanta, GA, 2019.

[13] Cui F.L., Qin L.X., Zhang G.S., Yao X.J., Du J., Binding of daunorubicin to human serum albumin using molecular modeling and its analytical application, Int $\mathrm{J}$ Biol Macromol 42 (2008) 221-228.

[14] Carter D.C., Crystallographic Survey of Albumin Drug Interaction and Preliminary Applications in Cancer Chemotherapy, in: D.J. A. and D.P. R. (Eds.), Burger's Medicinal Chemistry and Drug Discovery, New York, 2010, pp. 437-468.

[15] Schrödinger Release 2014-1, Schrödinger, LLC, New York, NY, 2014.

[16] Schrödinger Release 2014-1: ConfGen. version 2.7 S., LLC, New York,, 2014.

[17] Wells G.B., Structural answers and persistent questions about how nicotinic receptors work, Front Biosci 13 (2008) 5479-5510.

[18] Carter D.C., Ho J.X., Structure of serum albumin, Adv Protein Chem 45 (1994) 153203. 
[19] Diaz N., Suarez D., Sordo T.L., Merz K.M., Jr., Molecular dynamics study of the IIA binding site in human serum albumin: influence of the protonation state of Lys195 and Lys199, J Med Chem 44 (2001) 250-260.

[20] Walker J.E., Lysine residue 199 of human serum albumin is modified by acetylsalicyclic acid, FEBS Lett 66 (1976) 173-175.

[21] Friesner R.A., Murphy R.B., Repasky M.P., Frye L.L., Greenwood J.R., Halgren T.A., Sanschagrin P.C., Mainz D.T., Extra precision glide: docking and scoring incorporating a model of hydrophobic enclosure for protein-ligand complexes, J Med Chem 49 (2006) 6177 6196.

[22] Jorgensen W.L., Maxwell D.S., Tirado-Rives J., Development and testing of the OPLS all-atom force field on conformational energetics and properties of organic liquids, J. Am. Chem. Soc. 118 (1996) 11225-11236.

[23] Jaunet-Lahary T., Goupille A., Jacquemin D., Fleury F., Graton J., Laurent A.D., A Joint Theoretical and Experimental Study of the Behavior of the DIDS Inhibitor and its Derivatives, ChemPhysChem 17 (2016) 2434-2445.

[24] De Campos Vidal B., The use of the fluorescent probe 8-anilinonaphthalene sulfate (ANS) for collagen and elastin histochemistry, J Histochem Cytochem 26 (1978) 196-201.

[25] Essassi D., Zini R., Tillement J.P., Use of 1-anilino-8-naphthalene sulfonate as a fluorescent probe in the investigation of drug interactions with human alpha-1-acid glycoprotein and serum albumin, J Pharm Sci 79 (1990) 9-13.

[26] Gasymov O.K., Glasgow B.J., ANS fluorescence: potential to augment the identification of the external binding sites of proteins, Biochim Biophys Acta 1774 (2007) 403-411.

[27] Slavik J., Anilinonaphthalene sulfonate as a probe of membrane composition and function, Biochim Biophys Acta 694 (1982) 1-25.

[28] Sudlow G., Birkett D.J., Wade D.N., The characterization of two specific drug binding sites on human serum albumin, Mol Pharmacol 11 (1975) 824-832.

[29] He X.M., Carter D.C., Atomic structure and chemistry of human serum albumin, Nature 358 (1992) 209-215.

[30] Bouvier M., Brown G.R., The induced circular dichroism of bilirubin complexed with the alpha-helix form of poly(L-lysine), Biochim Biophys Acta 991 (1989) 303-309.

[31] Goncharova I., Orlov S., Urbanova M., The location of the high- and low-affinity bilirubin-binding sites on serum albumin: ligand-competition analysis investigated by circular dichroism, Biophys Chem 180-181 (2013) 55-65.

[32] Lighnter D.A., Wijekoon W.M., Zhang M.H., Understanding bilirubin conformation and binding. Circular dichroism of human serum albumin complexes with bilirubin and its esters, J Biol Chem 263 (1988) 16669-16676.

[33] Knudsen A., Pedersen A.O., Brodersen R., Spectroscopic properties of bilirubinhuman serum albumin complexes: a stoichiometric analysis, Arch Biochem Biophys 244 (1986) 273-284.

[34] Jacobsen J., Brodersen R., Albumin-bilirubin binding mechanism, J Biol Chem 258 (1983) 6319-6326.

[35] Zunszain P.A., Ghuman J., McDonagh A.F., Curry S., Crystallographic analysis of human serum albumin complexed with 4Z,15E-bilirubin-IXalpha, J Mol Biol 381 (2008) 394406.

[36] Sochacka J., Application of phenol red as a marker ligand for bilirubin binding site at subdomain IIA on human serum albumin, J Photochem Photobiol B 151 (2015) 89-99.

[37] Minomo A., Ishima Y., Kragh-Hansen U., Chuang V.T., Uchida M., Taguchi K., Watanabe H., Maruyama T., Morioka H., Otagiri M., Biological characteristics of two lysines on human serum albumin in the high-affinity binding of 4Z,15Z-bilirubin-IXalpha revealed by phage display, FEBS J 278 (2011) 4100-4111. 
[38] Zsila F., Subdomain IB is the third major drug binding region of human serum albumin: toward the three-sites model, Mol Pharm 10 (2013) 1668-1682.

[39] Ghuman J., Zunszain P.A., Petitpas I., Bhattacharya A.A., Otagiri M., Curry S., Structural basis of the drug-binding specificity of human serum albumin, J Mol Biol 353 (2005) 38-52.

[40] Curry S., Lessons from the crystallographic analysis of small molecule binding to human serum albumin, Drug Metab Pharmacokinet 24 (2009) 342-357.

[41] Helleday T., Homologous recombination in cancer development, treatment and development of drug resistance, Carcinogenesis 31 (2010) 955-960.

[42] Huang F., Mazin A.V., A small molecule inhibitor of human RAD51 potentiates breast cancer cell killing by therapeutic agents in mouse xenografts, PLoS One 9 (2014) e100993. 
<smiles>O=S(=O)(O)c1cc(N=C=S)ccc1/C=C/c1ccc(N=C=S)cc1S(=O)(=O)O</smiles>

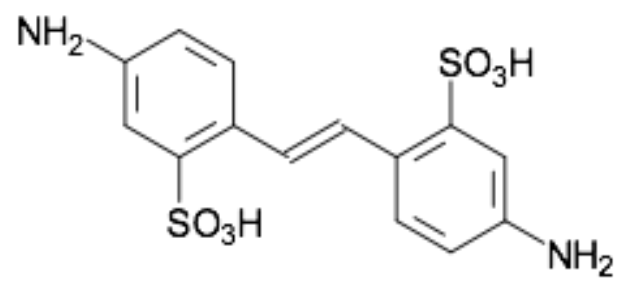

DADS<smiles>N#[N+]c1ccc(/C=C/c2ccc(N)cc2S(=O)(=O)O)c(S(=O)(=O)O)c1</smiles>

\section{DAZDS}

Figure 1. Chemical structures of DIDS and its amino and azido derivatives. 
A

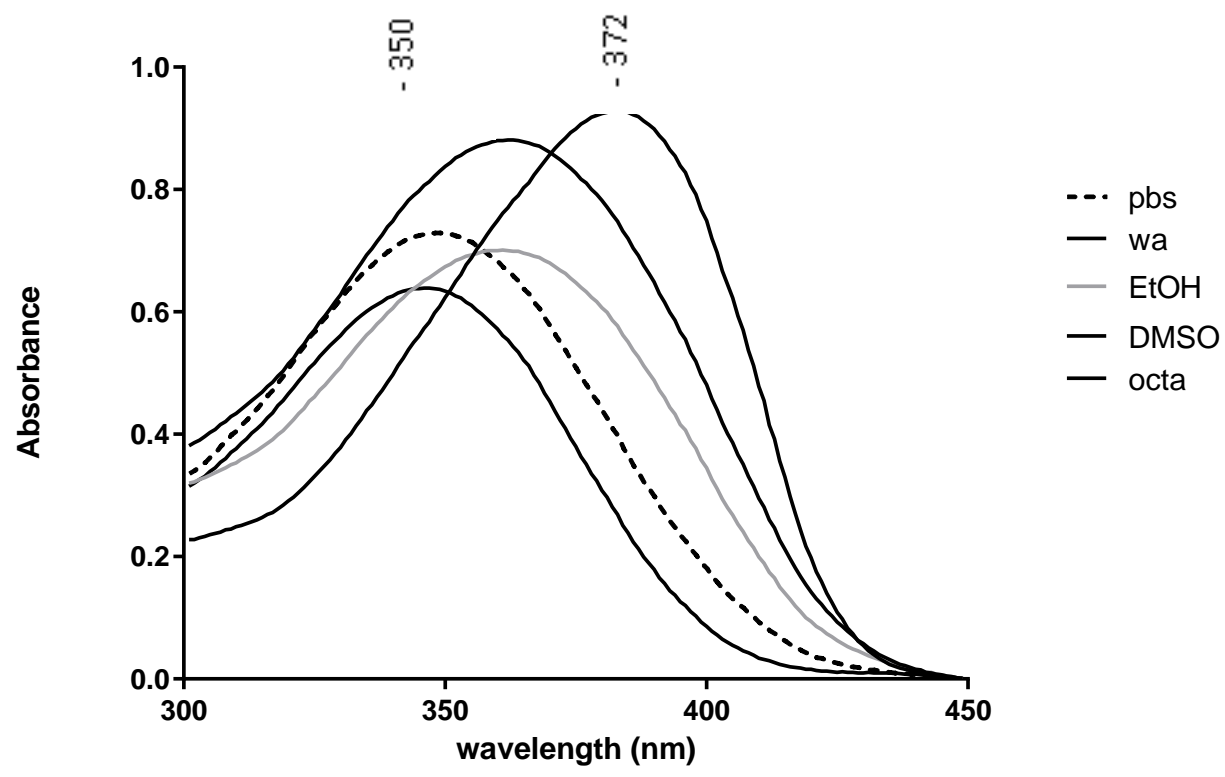

B

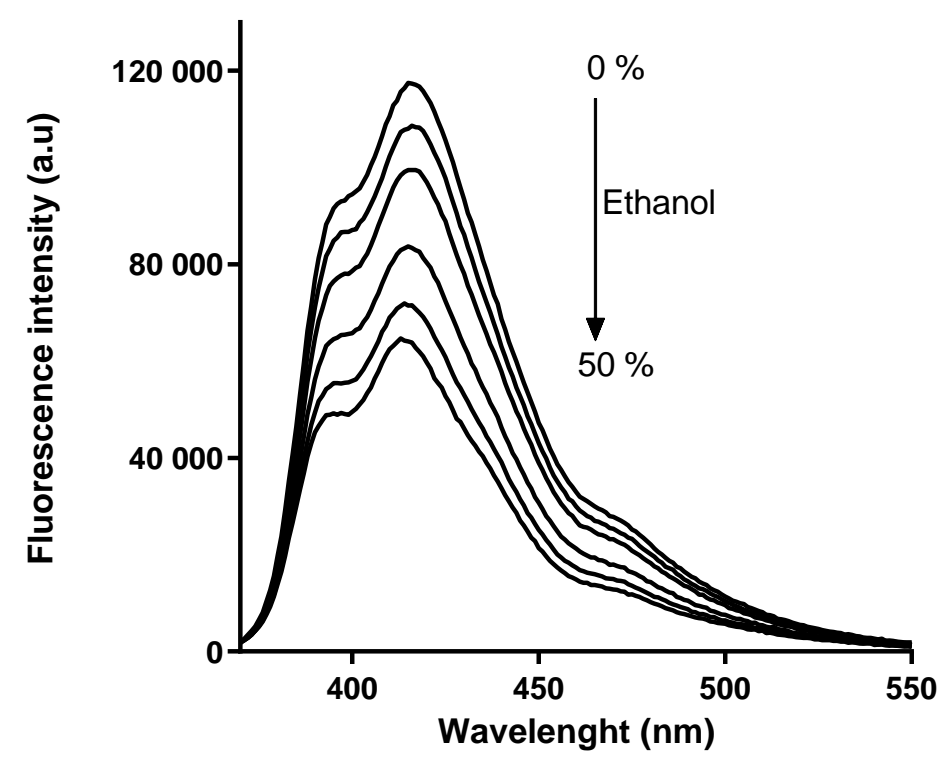

Figure 2. Effect of solvent polarity on the DIDS spectral characteristics.

(A) The absorption spectra of $20-\mu \mathrm{M}$ solutions of DIDS in different solvents. The absorbance maximum shifts to shorter wavelengths as the solvent polarity increases. Water (wa), phosphate-buffered saline (pbs), ethanol (EtOH), octanol (octa), and DMSO (D) have been used as solvents.

(B) The fluorescence spectra of $20-\mu \mathrm{M}$ solutions of DIDS containing different quantities of ethanol in water $(0,10,20,30,40$ and $50 \%)$. The quantum yield increases as the percentage of ethanol increases from 0 to $50 \%$. 
A

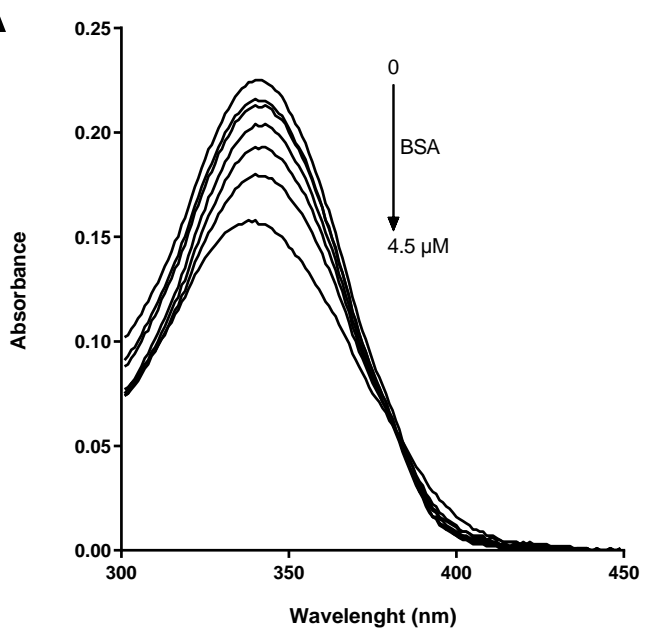

C

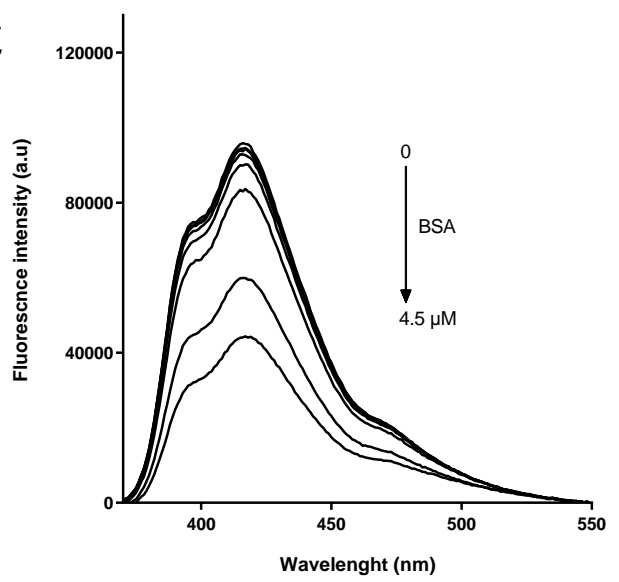

B
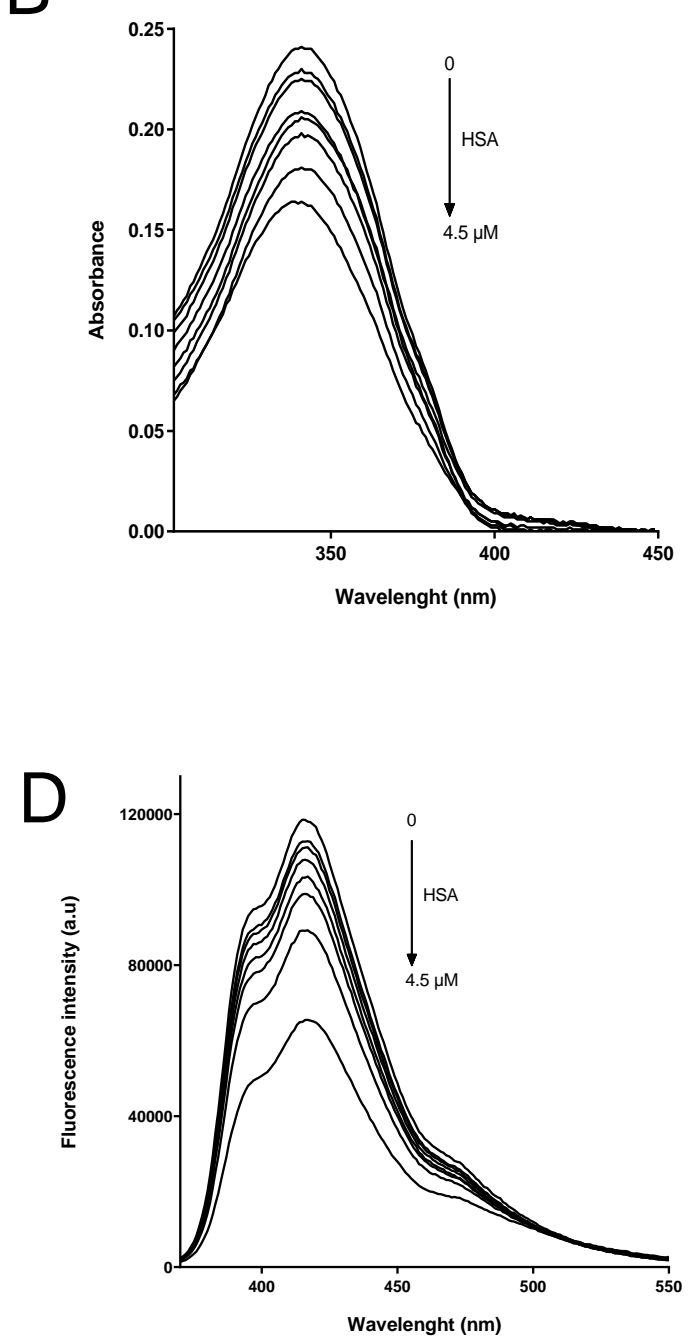

Figure 3. Optical effects of DIDS interactions with human and bovine serum albumins.

$20 \mu \mathrm{M}$ DIDS in PBS buffer was titrated by increasing concentrations of BSA (panels A and C) or HSA (panels B and D) up to $4.5 \mu \mathrm{M}$ for UV-vis absorbance and for fluorescence measurements. Fluorescence emission was monitored at the excitation wavelength of $350 \mathrm{~nm}$. 

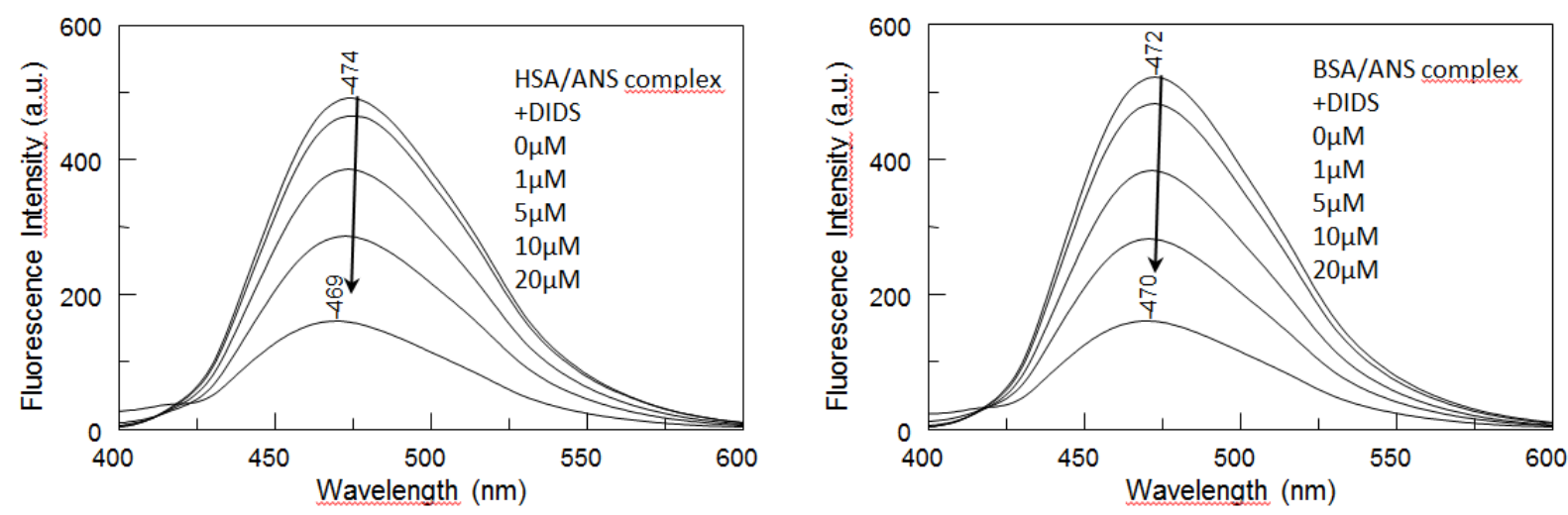

Figure 4. DIDS-induced variations of the ANS fluorescence emission.

The fluorescence spectra of albumin-bound ANS at a concentration of $10 \mu \mathrm{M}$ measured using an excitation wavelength of $370 \mathrm{~nm}$ at different DIDS concentrations. The concentrations of HSA (left) and BSA (right) during the titrations where $10 \mu \mathrm{M}$. The DIDS concentration in the solution was increased successively during titration: $1,5,10$, and $20 \mu \mathrm{M}$. 


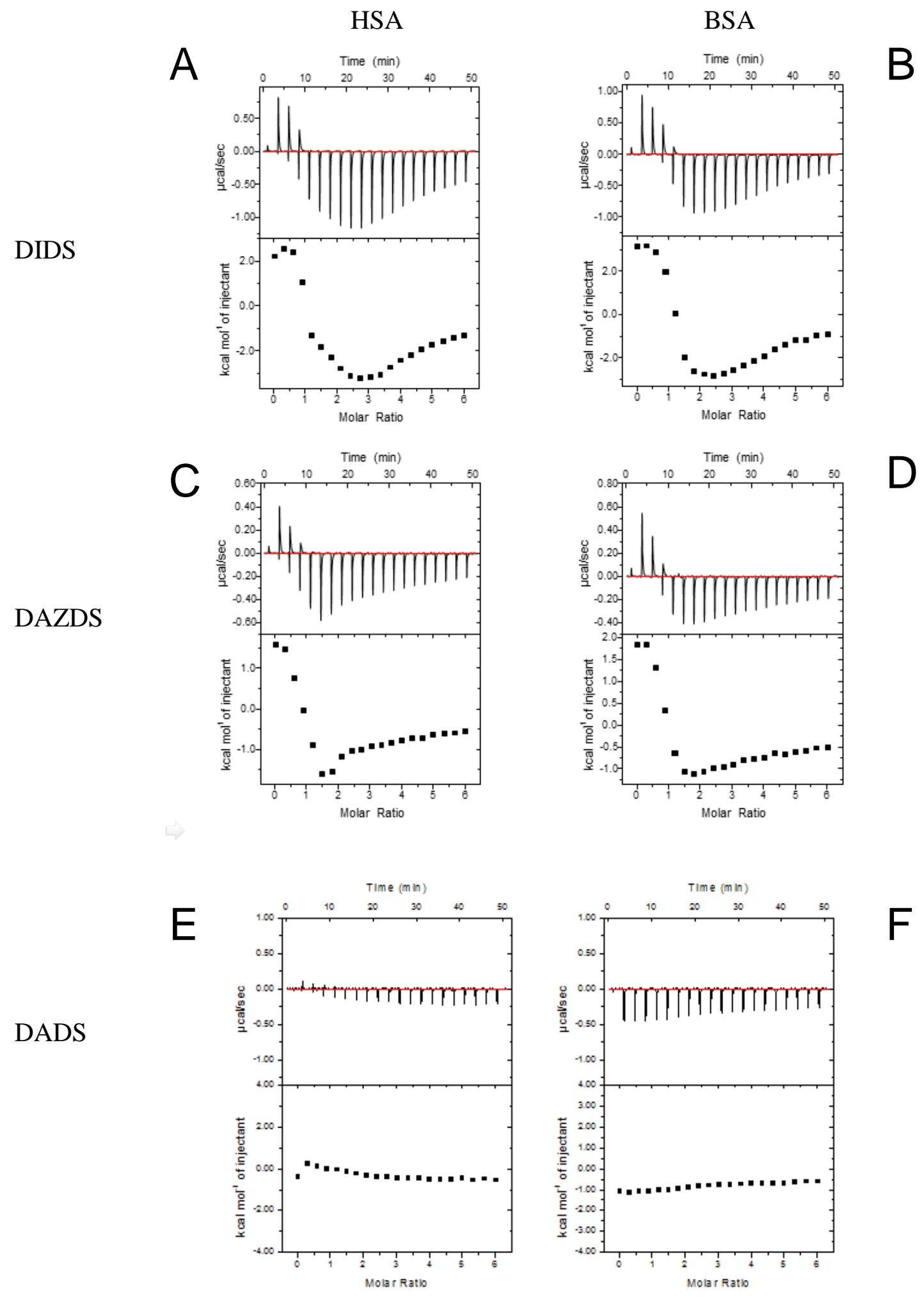

Figure 5. Isothermal titration calorimetry of DIDS derivatives in the complexes with human or bovine serum albumin. HSA and BSA at the concentrations of $70 \mu \mathrm{M}$ were titrated by 
DIDS (A and B), DAZDS (C and D) or DADS (E and F). The ligands dissolved in PBS were injected at a concentration of $2 \mathrm{mM}$.

For each binding isotherm, upper panel represents raw data and lower panel shows the integrated data fitted by using the two set of sites model from Microcal Origin software. 

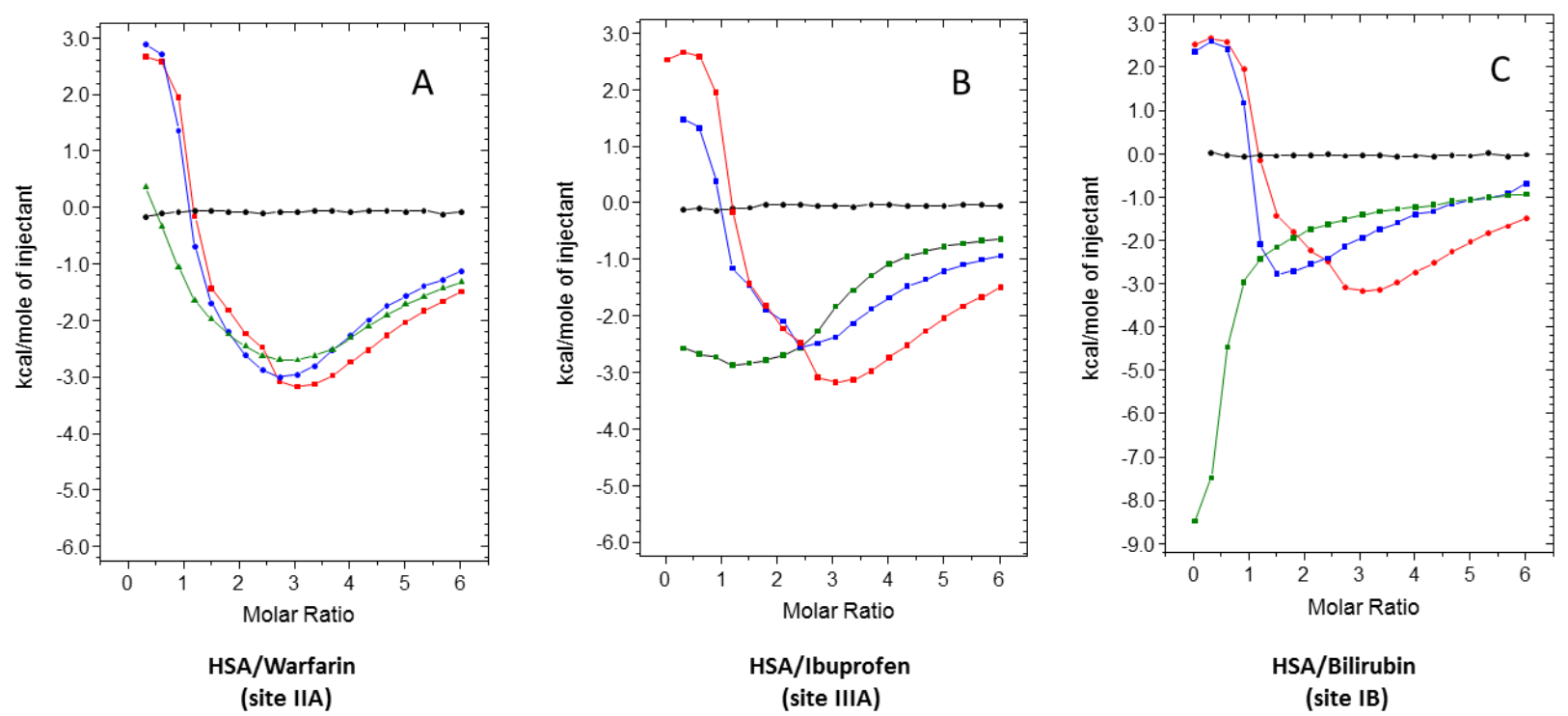

Figure 6. Identification of DIDS binding sites in HSA by binding competition.

HSA at a concentration of $70 \mu \mathrm{M}$ was preincubated with competing ligands for one hour in PBS at $22^{\circ} \mathrm{C}$. Warfarine and bilirubin were at a concentration of 50 (blue) or $500 \mu \mathrm{M}$ (green) and ibuprofen was at a concentration of 35 (blue) or $350 \mu \mathrm{M}$ (green). Preincubation of HSA with (A) warfarin, (B) ibuprofen, or (C) bilirubin was performed to occupy their respective sites in subdomains IIA, IIIA, or IB. HSA alone (red) or competitor-bound HSA were titrated by DIDS at increasing concentrations from a DIDS solution at $2 \mathrm{mM}$. ITC titrations without protein are shown in black. 
A
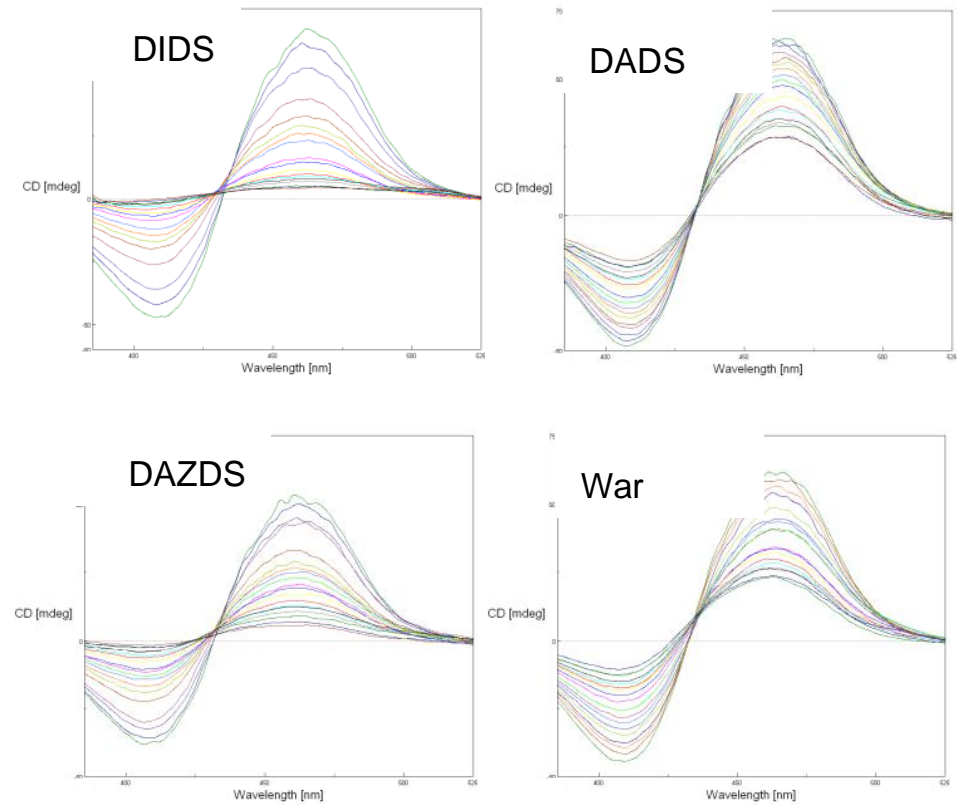

B

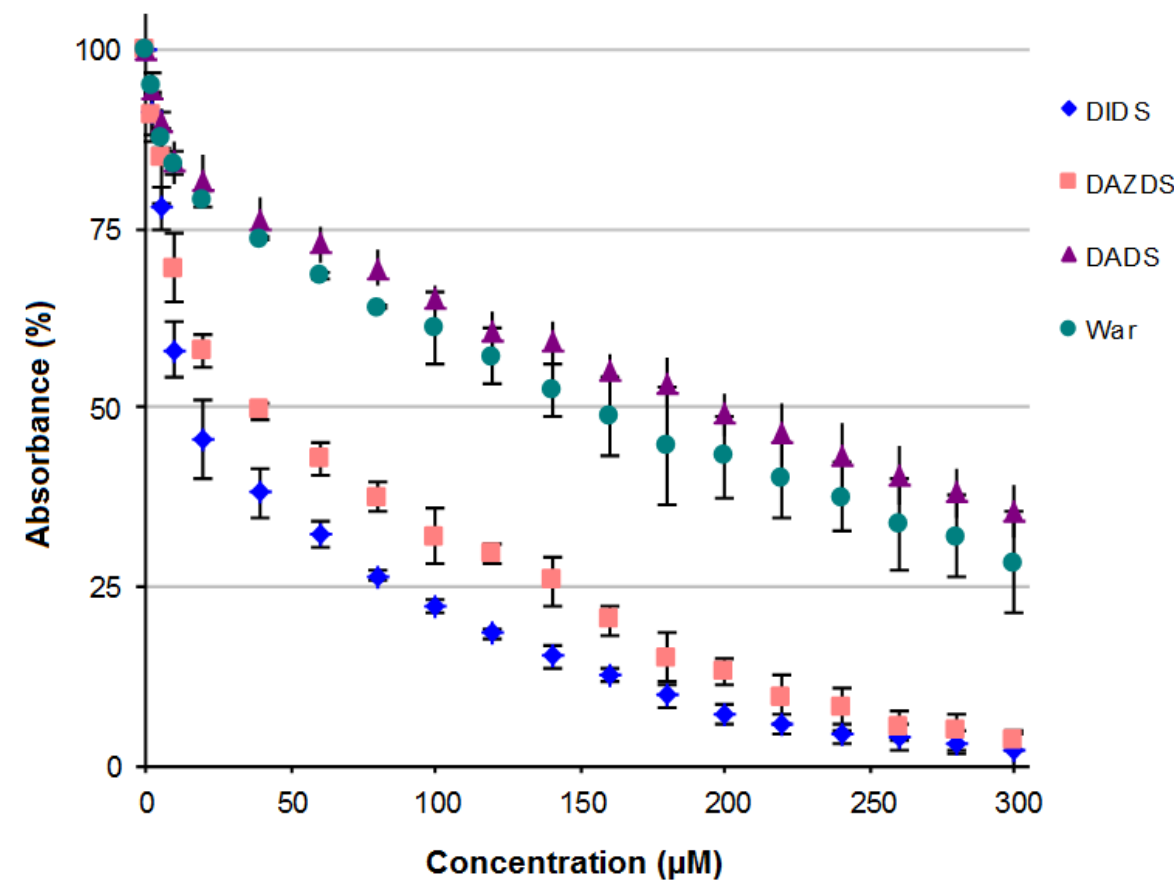

Figure 7. Probing of binding site IB by titration of the HSA/bilirubin complex.

(A) HSA at a concentration of $70 \mu \mathrm{M}$ was complexed with $50-\mu \mathrm{M}$ bilirubin. The HSA/BR complex was titrated by the drug with the concentration increasing from 0 to $300 \mu \mathrm{M}$.

(B) Induced circular dichroism signal measured at $410 \mathrm{~nm}$. 

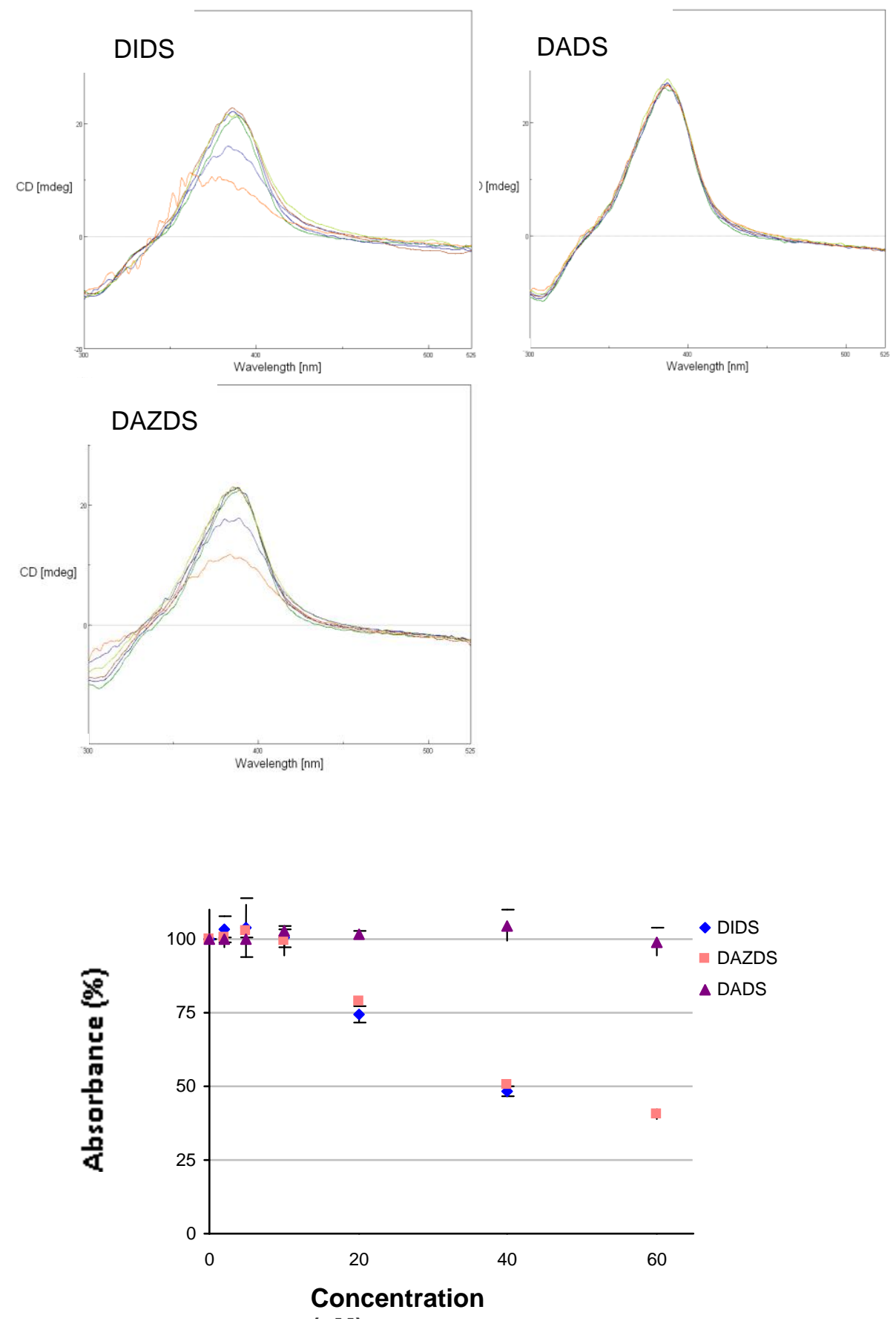

Figure 8. Probing of binding site IB by titration of the HSA/biverdin complex.

(A) HSA at a concentration of $70 \mu \mathrm{M}$ was complexed with $50-\mu \mathrm{M}$ BV. The HSA/BV complex was titrated by the stilbene derivative with the concentration increasing from 0 to 60 $\mu \mathrm{M}$.

(B) Induced circular dichroism signal measured at $410 \mathrm{~nm}$. 


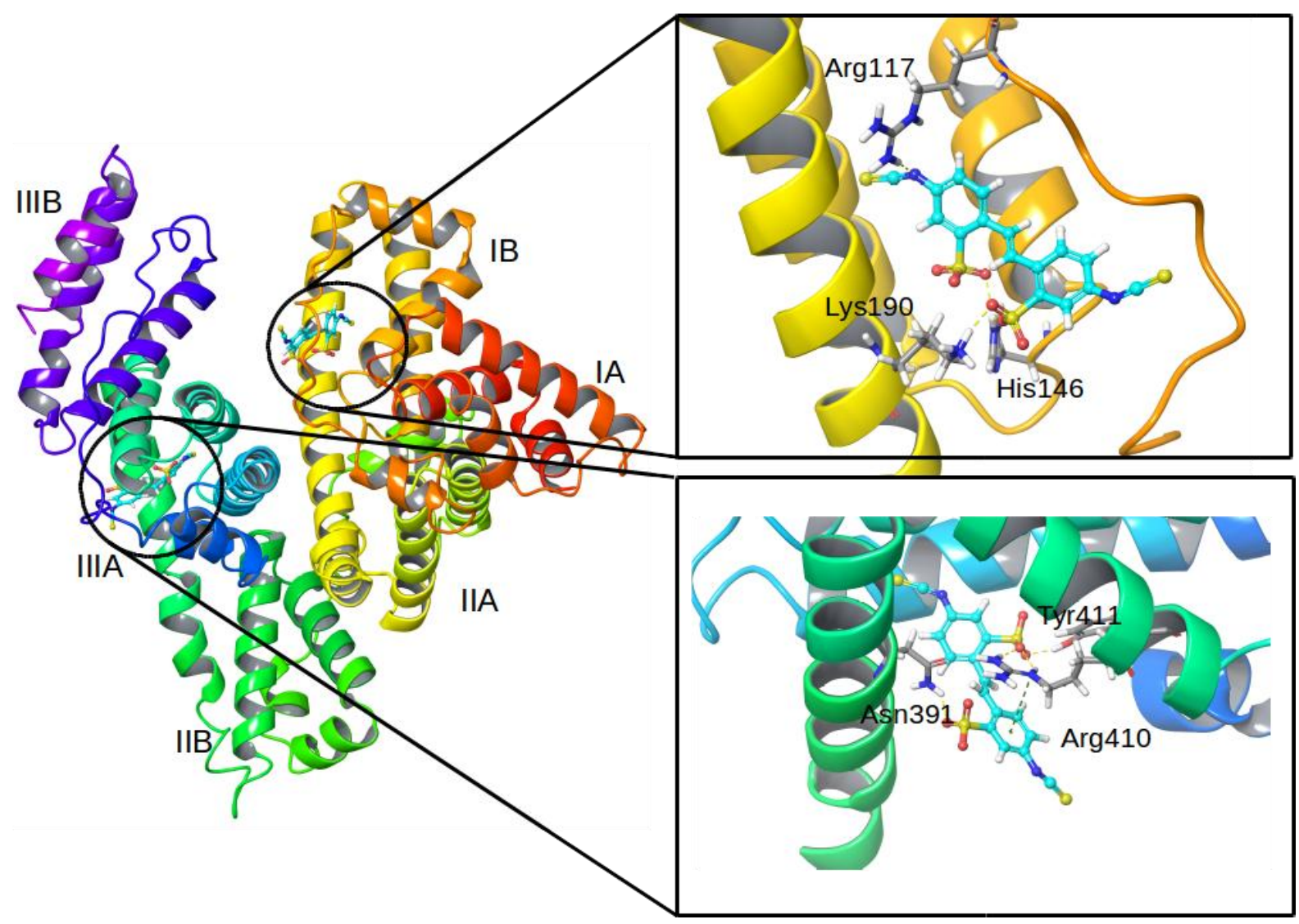

Figure 9. Left, schematic representation of the HSA protein with the predicted poses of DIDS in the IB and IIIA binding sites. Right, the main residues interacting with DIDS in the IB (top) and IIIA (bottom) binding sites. Carbon atoms of DIDS are shown in cyan; carbon atoms of the interacting residues are shown in gray. Nitrogen, oxygen, and sulfur atoms are shown, respectively, in blue, red, and yellow. 


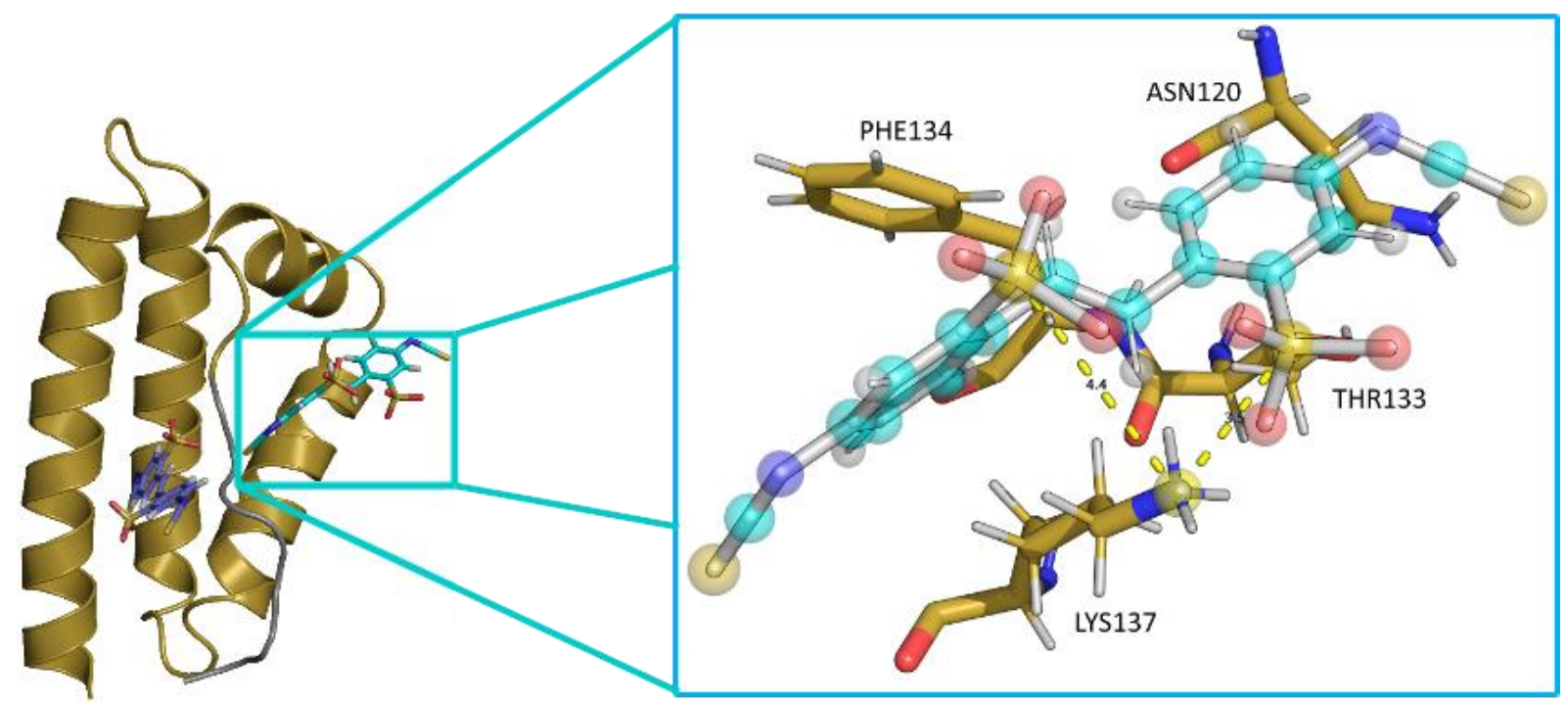

Figure S1. Left, schematic representation the IB binding site with the predicted poses of two DIDS in the IB binding site. Right, the main residues interacting with the second DIDS in IB. 


\begin{tabular}{|c|c|c|c|c|c|c|c|c|}
\hline & \multicolumn{4}{|c|}{ Interaction Site 1: high Affinity } & \multicolumn{4}{|c|}{ Interaction Site 2: low Affinity } \\
\hline & $\mathrm{N}_{1}$ & $\mathrm{Ka}_{1}\left(\mathrm{M}^{-1}\right)$ & $\begin{array}{c}\Delta \mathrm{H}_{1} \\
(\mathrm{cal} / \mathrm{mol})\end{array}$ & $\begin{array}{c}\Delta \mathrm{S}_{1} \\
(\mathrm{cal} / \mathrm{mol} / \mathrm{deg})\end{array}$ & $\mathrm{N}_{2}$ & $\mathrm{Ka}_{2}\left(\mathrm{M}^{-1}\right)$ & $\begin{array}{c}\Delta \mathrm{H}_{2} \\
(\mathrm{cal} / \mathrm{mol})\end{array}$ & $\begin{array}{c}\Delta S_{2} \\
(\mathrm{cal} / \mathrm{mol} / \mathrm{de} \\
\mathrm{g})\end{array}$ \\
\hline HSA & $\begin{array}{c}0.93 \\
+/-0.05\end{array}$ & $\begin{array}{r}3.3710^{6} \\
+/-1.7910^{6}\end{array}$ & $\begin{array}{r}4310 \\
+/-922\end{array}$ & $\begin{array}{l}42.8 \\
+/-2\end{array}$ & $\begin{array}{c}3.73 \\
+/-0.61\end{array}$ & $\begin{array}{c}3.1610^{4} \\
+/-1.5010^{4}\end{array}$ & $\begin{array}{l}-4988.3 \\
+/-1360\end{array}$ & $\begin{array}{l}3.47 \\
+/-6\end{array}$ \\
\hline BSA & $\begin{array}{c}1.04 \\
+/-0.25\end{array}$ & $\begin{array}{r}2.0810^{6} \\
+/-0.5910^{6}\end{array}$ & $\begin{array}{r}3827.3 \\
+/-675\end{array}$ & $\begin{array}{l}42.1 \\
+/-2\end{array}$ & $\begin{array}{r}3.23 \\
+/-0.76\end{array}$ & $\begin{array}{c}1.7110^{4} \\
+/-0.2610^{3}\end{array}$ & $\begin{array}{l}-4237.0 \\
+/-512\end{array}$ & $\begin{array}{l}5.31 \\
+/-2\end{array}$ \\
\hline
\end{tabular}

Table 1. Binding and thermodynamic parameters for DIDS interactions with HSA or BSA. HSA and BSA at the concentrations of $70 \mu \mathrm{M}$ were titrated by DIDS. The data are derived from at least four ITC experiments performed in PBS at $\mathrm{pH} 7.5$ and $22^{\circ} \mathrm{C}$. 


\begin{tabular}{|c|c|c|c|c|c|c|c|c|}
\hline & \multicolumn{4}{|c|}{ Interaction Site 1: high Affinity } & \multicolumn{4}{|c|}{ Interaction Site 2: low Affinity } \\
\hline & $\mathrm{N}_{1}$ & $\mathrm{Ka}_{1}\left(\mathrm{M}^{-1}\right)$ & $\begin{array}{c}\Delta \mathrm{H}_{1} \\
\text { (cal } / \mathrm{mol})\end{array}$ & $\begin{array}{c}\Delta \mathrm{S}_{1} \\
(\mathrm{cal} / \mathrm{mol} / \mathrm{deg})\end{array}$ & $\mathrm{N}_{2}$ & $\mathrm{Ka}_{2}\left(\mathrm{M}^{-1}\right)$ & $\begin{array}{c}\Delta \mathrm{H}_{2} \\
\text { (cal } / \mathrm{mol})\end{array}$ & $\begin{array}{c}\Delta \mathrm{S}_{2} \\
(\mathrm{cal} / \mathrm{mol} / \mathrm{deg})\end{array}$ \\
\hline HSA & 0.844 & $\begin{array}{r}4.1210^{5} \\
+/-1.1210^{5}\end{array}$ & $\begin{array}{r}2366 \\
+/-204\end{array}$ & 33.70 & ND & ND & ND & ND \\
\hline $\mathrm{BSA}$ & 0.788 & $\begin{array}{r}9.1210^{5} \\
+/-1.5810^{5}\end{array}$ & $\begin{array}{c}2028 \\
+/-48.5\end{array}$ & 34.10 & ND & ND & ND & ND \\
\hline
\end{tabular}

Table 2. Binding and thermodynamic parameters for DAZDS interactions with HSA or BSA. HSA and BSA at the concentrations of $70 \mu \mathrm{M}$ were titrated by DIDS. The data are derived from at least four ITC experiments performed in PBS at pH 7.5 and $22^{\circ} \mathrm{C}$. 